\title{
Structural and Optical Characterizations of Ge Nanostructures Fabricated by RF Magnetron Sputtering and Rapid Thermal Processing
}

\author{
A.F. Abd Rahim ${ }^{a, b, *}$, M.R. Hashim ${ }^{a}$, M. Rusop ${ }^{c}$ And M.M. Jumidali ${ }^{a, d}$ \\ ${ }^{a}$ Nano-Optoelectronics Research Laboratory, School of Physics, Universiti Sains Malaysia, 11800-Penang, Malaysia \\ ${ }^{b}$ Faculty of Electrical Engineering, Universiti Teknologi MARA, 13500 Permatang Pauh, Pulau Pinang, Malaysia \\ ${ }^{c}$ Faculty of Electrical Engineering, Universiti Teknologi MARA, 40450 Shah Alam, Selangor, Malaysia \\ ${ }^{d}$ Department of Applied Science, Universiti Teknologi MARA, 13500 Permatang Pauh, Pulau Pinang, Malaysia \\ In this work, we use a simple and cost effective technique of sputtering followed by the rapid thermal \\ processing at $900^{\circ} \mathrm{C}$ for $30 \mathrm{~s}$ to form Ge nanostructures on the $\mathrm{Si}(100)$ substrate. A layer of Ge (300 $\left.\mathrm{nm}\right)$ and $\mathrm{Si}$ \\ cap layer $(100 \mathrm{~nm})$ were deposited using RF magnetron sputtering. Two samples were prepared: Ge layer with Si \\ capping ( $\mathrm{Si} / \mathrm{Ge} / \mathrm{Si}$ ) and Ge layer without $\mathrm{Si}$ capping (Ge/Si). Scanning electron microscopy shows that subsequent \\ annealing in a rapid thermal processing gives uniformed Ge or SiGe islands with an estimated size of 100-500 $\mathrm{nm}$. \\ For the Ge/Si sample, under post growth annealing there had vanished the deposited Ge layer as confirmed by \\ energy dispersive X-ray analysis. Atomic force microscopy shows that the surface roughness increases by a factor \\ of $15.55 \%$ as the islands formed. The Raman spectrum shows that good crystalline structures of the Ge and SiGe \\ peaks are produced. High resolution X-ray diffraction reveals cubic and tetragonal Ge phases with estimated \\ average crystallite sizes of $42 \mathrm{~nm}$ and $20 \mathrm{~nm}$, respectively. The results showed that it is possible to grow high \\ quality Ge and SiGe nanostructures using a simple technique of sputtering for potential applications in photonics \\ and high speed devices.
}

PACS: 68.55.ag, 68.60.Dv, 61.46.Hk, 78.67.Bf, 61.05.C-

\section{Introduction}

$\mathrm{Ge} / \mathrm{Si}$ nanostructure has attracted great attention for its potential application in optoelectronic devices. Germanium is an interesting group IV semiconductor for its high carrier mobility and its display of unique optical properties at the nanoscale which holds potential for the applications in photonics and high speed electronics [1]. A variety of techniques have been employed to grow such structures, the most popular one is the self-assembled growth nanometer islands in a highly strained system using the molecular beam epitaxy (MBE) and low pressure chemical vapor deposition (LPCVD) techniques $[2,3]$. However, these techniques require a sophisticated machine and the cost is very high. On the other hand, Baharin and Hashim [4] have shown a possible way of growing Ge islands using low cost methods of thermal evaporator and rapid thermal annealing. The challenge in this technique is to control the size and position of the Ge islands because of the non-epitaxial nature of the deposited Ge layers. Nonetheless, the non-uniform Ge islands beneath the Ni contact on the $\mathrm{Si}$ substrate have

* corresponding author; e-mail: alhan570@ppinang.uitm.edu.my been shown to suppress the dark current and enhance the photocurrent of metal-semiconductor-metal photodetector. A good Ge epitaxial layer can be produced using plasma-assisted deposition. Limited reports are available in the literature on the growth properties of Ge nanostructures on the Si substrate using plasma-assisted deposition. Das et al. [5] in their study have demonstrated the potential growth of Ge islands on $\mathrm{Si}(001)$ substrates and in $\mathrm{SiO}_{2}$ matrix using the simple radio frequency (RF) magnetron sputtering method. The islands were grown after subsequent annealing at different temperatures in $\mathrm{N}_{2}$ atmosphere for about $1 \mathrm{~h}$. In addition, rapid thermal processing (RTP) has shown to be very effective in increasing the growth or the recrystallisation of $\mathrm{Si}$ and $\mathrm{Ge}$ compared to the conventional furnace annealing [6]. Hence in this work, the cost effective and simple technique of RF magnetron sputtering coupled with subsequent RTP will be utilized to grow uniformed Ge islands on the $\mathrm{Si}(100)$ substrate. Structural and optical characterizations of the structures will be discussed.

\section{Experimental procedures}

Several $n$-type $\langle 100\rangle$-oriented silicon wafers with a resistivity of $1-10 \Omega \mathrm{cm}$ were cleaned in a wet chemical 
etch process, using the RCA cleaning method before the Ge layer was deposited. To elaborate, after cleaning, a Ge with $99.999 \%$ purity commercial source was then deposited (estimated thickness $\approx 300 \mathrm{~nm}$ ) onto the Si substrate by using the Edwards A500 RF sputtering unit with RF power of $110 \mathrm{~W}$ for $30 \mathrm{~min}$ in a vacuum condition with a background pressure of $2.5 \times 10^{-5}$ Torr. This is followed by the deposition of the Si capping layer (estimated thickness $\approx 200 \mathrm{~nm}$ ) by the same method at $\mathrm{RF}$ power of $150 \mathrm{~W}$ for $60 \mathrm{~min}$. After that, the sample underwent rapid thermal annealing at $900^{\circ} \mathrm{C}$ for $30 \mathrm{~s}$ in flowing $\mathrm{N}_{2}$ at $500 \mathrm{sccm}$ using Jipelec JetFirst 100 RTP to form the Ge islands. Three samples were prepared: as deposited $\mathrm{Si} / \mathrm{Ge} / \mathrm{Si}$ layer (as dep), Ge island on the $\mathrm{Si}$ substrate $(\mathrm{Ge} / \mathrm{Si})$ and $\mathrm{Ge}$ islands on the Si substrate with its $\mathrm{Si}$ capping layer $(\mathrm{Si} / \mathrm{Ge} / \mathrm{Si})$. Structural and optical analyses of the samples were performed using JEOL JSM-6460LV scanning electron microscope (SEM), an energy dispersive X-ray analysis (EDX), Jobin Yvon HR800UV Raman spectroscopy and a high-resolution PANalytical $\mathrm{X}$-ray diffractometer (HR-XRD). All measurements were made at room temperature.

\section{Results and discussion}

Figure 1 shows SEM images of the as deposited, Ge/Si and $\mathrm{Si} / \mathrm{Ge} / \mathrm{Si}$ samples. The as deposited sample showed a smooth surface with substantial Si and Ge weight contents of about $41.15 \%$ and $39.05 \%$, respectively, as shown by the EDX spectra on the rightside of Fig. 1a. A very low oxide content is also found in the structure suggesting the possibility of $\mathrm{SiO}_{2}$ being formed. The $\mathrm{Ge} / \mathrm{Si}$ sample in Fig. 1b shows rough and spongy structures emerged after RTP compared to the as deposited sample. While for the $\mathrm{Si} / \mathrm{Ge} / \mathrm{Si}$ sample which was put under rapid annealing of $900^{\circ} \mathrm{C}$ for $30 \mathrm{~s}$, the layer slowly emerged into uniform $\mathrm{Ge}$ or $\mathrm{SiGe}$ islands as can be seen from the $\mathrm{Si} / \mathrm{Ge} / \mathrm{Si}$ sample (Fig. 1c). The estimated Ge islands' size formed, ranged from $100 \mathrm{~nm}$ to $500 \mathrm{~nm}$. On the right of each sample there is the respective EDX of the samples. For the $\mathrm{Ge} / \mathrm{Si}$ and $\mathrm{Si} / \mathrm{Ge} / \mathrm{Si}$, the EDX was taken at 2 spots which was at the white spot (W) believed to be the islands and black spot (B) which was the area between the islands. For Ge/Si (Fig. 1b) both EDX spectra show only Si contents which confirms that the RTP had made vanished the Ge layer on the $\mathrm{Si}$ substrate. However, the $\mathrm{Si} / \mathrm{Ge} / \mathrm{Si}$ sample shows the presence of Ge while the presence of low Ge peak on the black spot suggests the presence of a thin wetting layer between the Ge islands. The presence of oxygen content suggests the possibility of GeO presence in the structures.

The surface morphology of the samples was examined from the atomic force microscopy (AFM) micrograph (Figs. 2a and b). As deposited $\mathrm{Si} / \mathrm{Ge} / \mathrm{Si}$ sample proves, the grains are uniformly distributed within the scanning area $(30 \mu \mathrm{m} \times 30 \mu \mathrm{m})$, with individual columnar grains extending upwards. The average grain height is found to be in the range of $8.97 \mathrm{~nm}$ and the root mean square

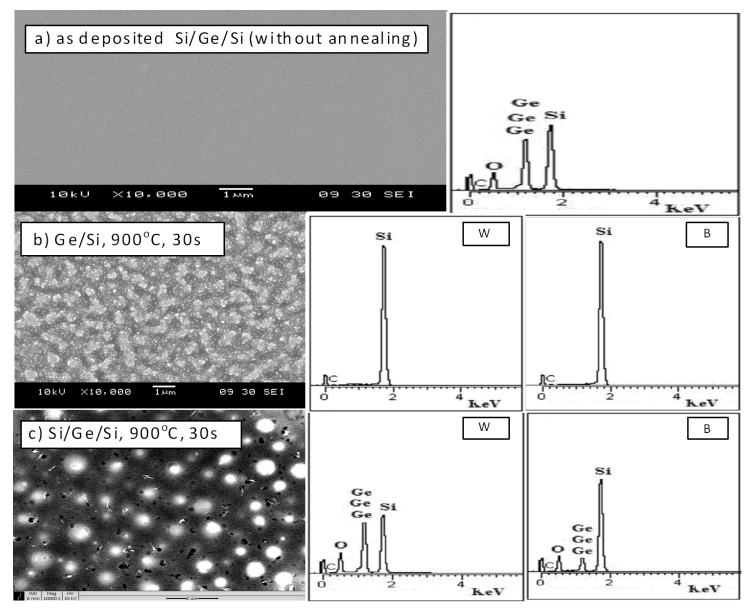

Fig. 1. SEM and EDX graphs of (a) as deposited $\mathrm{Si} / \mathrm{Ge} / \mathrm{Si}$, (b) Ge/Si, and (c) $\mathrm{Si} / \mathrm{Ge} / \mathrm{Si}: \mathrm{W}=$ white area and $\mathrm{B}=$ Black area.

(RMS) is equal to $3.4 \mathrm{~nm}$. This indicates that the deposited Si capping and Ge layer using the RF magnetron sputtering have exhibited a very smooth film surface for the subsequent Ge islands formation. The significant increase of the roughness of the surface, and the height of the islands have been observed on the $\mathrm{Si} / \mathrm{Ge} / \mathrm{Si}$ sample (Fig. 2b). Specifically the RMS of the surface roughness of $\mathrm{Si} / \mathrm{Ge} / \mathrm{Si}$ has increased to $52.87 \mathrm{~nm}$ which corresponds to $15.55 \%$ increase.

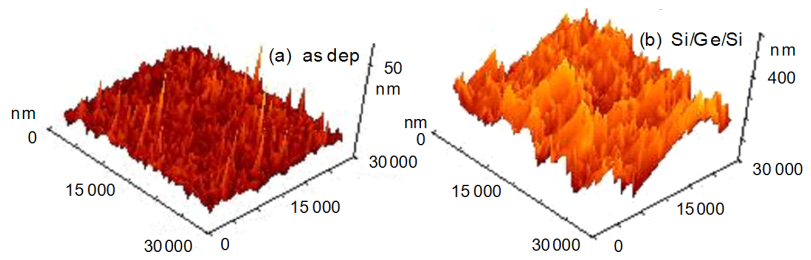

Fig. 2. AFM of (a) as deposited and (b) Si/Ge/Si samples at room temperature.

Figure 3 shows the Raman spectrum of the three samples taken at room temperature. In general, the as deposited sample shows no Raman peaks in the scan range indicating the absence of crystalline phases and the structure of the deposited film that could be disordered. However, the inset in Fig. 3 shows a low and broad hump centred at $274.9 \mathrm{~cm}^{-1}$ with full width at half maximum (FWHM) of $77.3 \mathrm{~cm}^{-1}$ corresponding to the amorphous Ge $[6,7]$. As the film was annealed at $900^{\circ} \mathrm{C}$ for $30 \mathrm{~s}$ ( $\mathrm{Si} / \mathrm{Ge} / \mathrm{Si}$ ), the appearance of pronounced Raman peak at $292.1 \mathrm{~cm}^{-1}$ with asymmetrical broadening over the low frequency side emerged, indicating that a good Ge nanocrystal had been obtained. This peak is attributed to the optical phonon contribution of the Ge-Ge stretching mode [5] and is red-shifted by $\approx 8 \mathrm{~cm}^{-1}$ as compared to that of the bulk Ge $\left(300 \mathrm{~cm}^{-1}\right)$ [8], which is in agreement with the phonon confinement theory pre- 


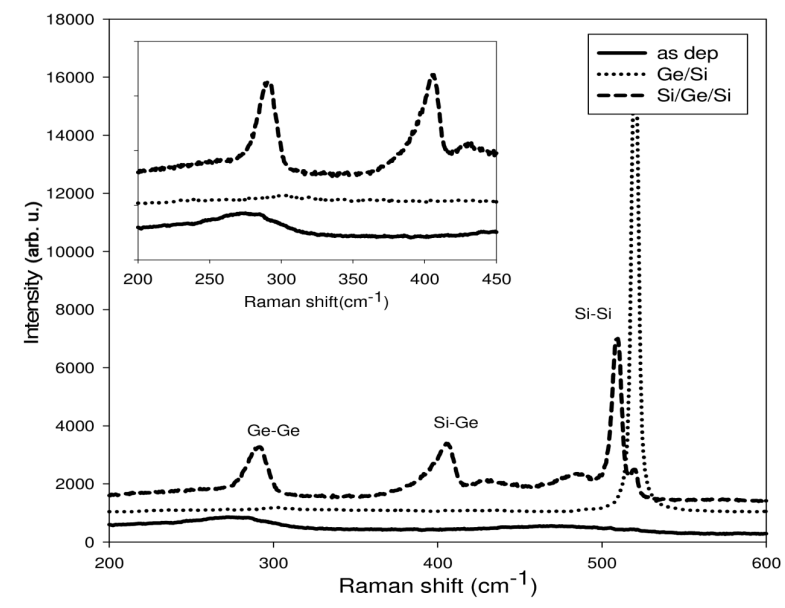

Fig. 3. Raman spectroscopy of as deposited, Ge/Si, and $\mathrm{Si} / \mathrm{Ge} / \mathrm{Si}$ at room temperature. Inset shows the enlarged Ge peak and SiGe peaks.

diction for nanocrystals [9] whereby as the average size decreases the Raman peak broadens and shifts slightly to lower frequencies. Another sharp peak at $405.2 \mathrm{~cm}^{-1}$ with FWHM of $16.9 \mathrm{~cm}^{-1}$ is also observed which corresponds to the $\mathrm{Si}-\mathrm{Ge}$ alloy mode [10]. In addition, there exist small peaks at $432.4 \mathrm{~cm}^{-1}$ and $484.9 \mathrm{~cm}^{-1}$ which belong to $\mathrm{Ge}-\mathrm{Si}$ and local $\mathrm{Si}-\mathrm{Si}$ vibration mode [11], indicating the intermixing of $\mathrm{Ge}-\mathrm{Si}$. The red-shifted bond of $\mathrm{Si}-\mathrm{Si}$ at $509.6 \mathrm{~cm}^{-1}$ demonstrates a tensile strain in the Si cap layer possibly caused by the difference in lattice parameters of $\mathrm{Ge}$ and $\mathrm{Si}$. For the Ge/Si sample, only the $\mathrm{Si}-\mathrm{Si}$ phonon mode at about $520 \mathrm{~cm}^{-1}$ is observed. This is in agreement with the previous EDX spectra which show only the Si content left after subsequent annealing in RTP. This shows that with Si cap layer, the film can adequately transform into uniformly good crystalline Ge and $\mathrm{SiGe}$ islands at rather high temperature during the annealing process. The $\mathrm{Si} / \mathrm{Ge} / \mathrm{Si}$ probably consists of relaxed Ge cores surrounded by the SiGe shells whereby the Si cap layer must be alloyed with Ge to form a SiGe shells around the Ge cores. It is possible that the Si cap layer plays a role in relieving stress and acts as a capping factor protecting the Ge core from getting oxidized [12].

Figure 4 shows the measured high resolution X-ray diffraction (HRXRD) of the three samples. The as-deposited and $\mathrm{Ge} / \mathrm{Si}$ samples spectra reveal the presence of only Si phases with the orthorhombic structure by (220) and (421). Another pronounced peaks at about $69^{\circ}$ and $82^{\circ}$ correspond to (400) and (440) reflections of the Si cubic structures. In general, the $\mathrm{Ge} / \mathrm{Si}$ sample shows decreasing intensity compared to as-deposited sample, except at $69^{\circ}$ where the peak for $\mathrm{Ge} / \mathrm{Si}$ is much stronger than the former. This suggests that in high temperature the top deposited Ge layer vanished and there left only the Si substrate beneath it, while the as-deposited sample reveals only the $\mathrm{Si}$ peak from the $\mathrm{Si}$ cap layer and the $\mathrm{Si}$ substrate. The $\mathrm{Si} / \mathrm{Ge} / \mathrm{Si}$ sample reveals Ge cubic phases

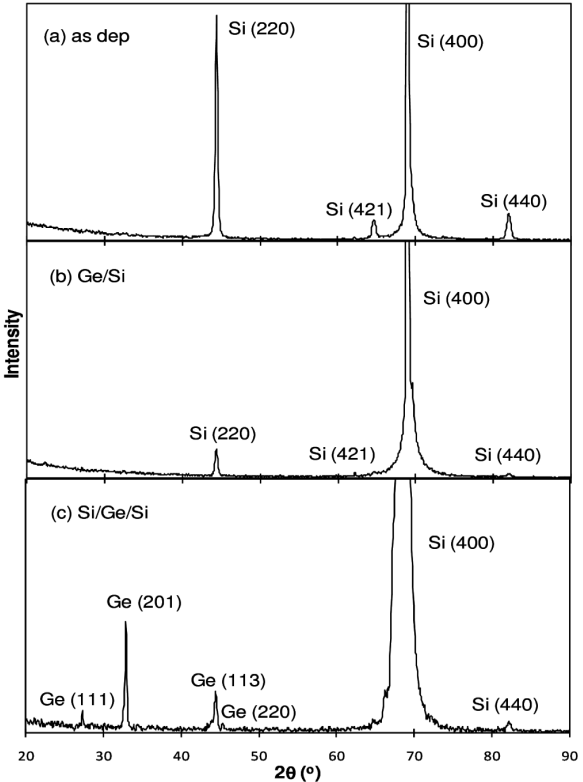

Fig. 4. HRXRD of (a) as deposited, (b) Ge/Si, and (c) $\mathrm{Si} / \mathrm{Ge} / \mathrm{Si}$ samples taken at room temperature.

by (111) and (220) and Ge tetragonal phases by (201) and (113), respectively. The estimated average Ge crystallites size using Scherrer's equation ranges from $42 \mathrm{~nm}$ (from the Ge cubic) to $20 \mathrm{~nm}$ (from the Ge tetragonal) phases. In addition, we can see that the dominant peak at about $2 \theta=69.1^{\circ}$ is the (400) diffraction from the $\mathrm{Si}$ substrate [13] and a small peak at $82.1^{\circ}$ belong to the cubic Si (440) reflection.

\section{Conclusions}

We have shown that it is possible to grow Ge and SiGe nanostructures on the $\mathrm{Si}(100)$ substrate by using a simple and cost-effective technique of the RF magnetron sputtering and rapid thermal processing. SEM showed that subsequent annealing in rapid thermal processing at $900^{\circ} \mathrm{C}$ for 30 s resulted in uniform Ge or SiGe islands with estimated sizes of 100-500 nm. The AFM shows that the surface roughness increased by a factor of $15.55 \%$ as the islands were formed. For the $\mathrm{Ge} / \mathrm{Si}$ sample, under post-growth annealing there vanished the deposited Ge layer as confirmed by EDX, Raman and XRD. The Raman spectrum shows that good crystalline structures of the Ge and SiGe peaks can be produced from the annealed sample with the Si cap layer. HRXRD reveals cubic and tetragonal Ge phases with estimated average crystallites size ranging from $42 \mathrm{~nm}$ to $20 \mathrm{~nm}$, respectively, from the $\mathrm{Si} / \mathrm{Ge} / \mathrm{Si}$ sample. The presence of the Si cap layer on top of the Ge layer deposited has shown to prevent the Ge layer from vaporizing and helps to form good Ge and SiGe nanostructures. The results exhibited that it is possible to grow high quality Ge and SiGe nanostructures using conventional techniques for potential applications in photonics and high speed devices. 


\section{Acknowledgments}

The author wishes to thank Universiti Teknologi MARA for financial assistance and members of Nano-Optoelectronics Lab, USM and NANO-SciTech Centre, UiTM Shah Alam for endless technical assistance. Support from the Fundamental Research Grant (FRGS) grant no. 600-RMI/ST/FRGS 5/3/Fst (143/2010) is gratefully acknowledged.

\section{References}

[1] C.-B. Jin, J.-E. Yang, M.-H. Jo, Appl. Phys. Lett. 88, 193105 (2006).

[2] M.H. Cheng, W.X. Ni, G.L. Luo, S.C. Huang, J.J. Chang, C.Y. Lee, Thin Solid Films 517, 57 (2008).

[3] Z.F. Krasil'nik, P. Lytvyn, D.N. Lobanov, N. Mestres, A.V. Novikov, J. Pascual, M.Y. Valakh, V.A. Yukhymchuk, Nanotechnology 13, 81 (2002).

[4] A. Baharin, M.R. Hashim, Semicond. Sci. Technol. 22, 905 (2007).
[5] K. Das, M.L.N. Goswami, A. Dhar, B.K. Mathur, S.K. Ray, Nanotechnology 18, 175301 (2007).

[6] W.K. Choi, S. Kanakaraju, Z.X. Shen, W.S. Li, Appl. Surf. Sci. 144-145, 697 (1999).

[7] Y. Sasaki, C. Horie, Phys. Rev. B 47, 3811 (1993).

[8] D.R. dos Santos, I.L. Torriani, Solid State Commun. 85, 307 (1993).

[9] R.J. Kashtiban, S.R.C. Pinto, U. Bangert, A.G. Rolo, A. Chahboun, M.J.M. Gomes, A.J. Harvey, J. Phys. Conf. Series 209, 012060 (2010).

[10] M. Fujii, S. Hayashi, K. Yamamoto, Appl. Phys. Lett. 57, 2692 (1990).

[11] A.V. Kolobov, Y. Maeda, K. Tanaka, J. Appl. Phys. 88, 3285 (2000).

[12] K.U. Joshi, D. Kabiraj, A.M. Narsale, D.K. Avasthi, T.K. Gundurao, T.N. Warang, D.C. Kothari, Surf. Coat. Technol. 203, 2497 (2009).

[13] J. Huang, Z. Ye, B. Zhao, X. Ma, Y. Wang, D. Que, Appl. Phys. Lett. 78, 1858 (2001). 